\title{
Reoquafia
}

Malaysian Tournal of Society and Space

\section{Cabaran dalam menguruskan pendatang asing tanpa izin di depot tahanan imigresen Malaysia}

\author{
Nurina Awanis Mohamed, Mohd Na'eim Ajis, Zawiyah Md. Zain \\ Pusat Pengajian Kerajaan, Kolej Undang-Undang, Kerajaan dan Pengajian Antarabangsa, \\ Universiti Utara Malaysia
}

Correspondence: Nurina Awanis Mohamed (email: mnurinawanis@live.com.my)

Received: 14 April 2019; Accepted: 17 June 2019; Published: 22 August 2019

\begin{abstract}
Abstrak
Kebanyakan negara maju menggunakan pendekatan depot tahanan sebagai instrumen utama dalam mengawal dan mengusir pendatang asing tanpa izin (PATI). Instrumen ini turut dipraktikkan di negara-negara membangun, termasuklah Malaysia. Terdapat beberapa prosedur dan standard yang perlu dipatuhi oleh pihak kerajaan dalam menguruskan tahanan yang melibatkan PATI seperti yang termaktub dalam peruntukan undang-undang antarabangsa. Namun, peruntukan undang-undang tersebut kadang-kala sukar untuk dipenuhi disebabkan oleh beberapa kekangan dan masalah yang terpaksa dihadapi. Kertas kerja ini dilakukan bertujuan bagi meneliti cabaran yang terpaksa dihadapi dalam menguruskan PATI yang ditahan di depot tahanan imigresen. Penelitian kajian hanya tertumpu di depot tahanan Belantik di Sik, Kedah. Bagi mencapai objektif kajian ini, kaedah kualitatif berbentuk temu bual secara mendalam digunakan melibatkan beberapa pegawai di depot tahanan Belantik. Selain itu, kajian turut menggunakan kaedah perbincangan secara berkumpulan melibatkan 150 orang tahanan. Hasil temu bual mendapati bahawa terdapat lima cabaran yang dihadapi oleh pihak imigresen dalam menguruskan tahanan, iaitu menyediakan kemudahan penginapan, proses mengenal pasti identiti tahanan, kesukaran untuk berkomunikasi dengan tahanan, sistem teknologi yang terhad dan sering mengalami masalah ketiadaan bekalan air. Kesimpulannya, kerajaan perlu membuat pemantauan di setiap depot tahanan dari semasa ke semasa bagi memastikan pihak depot tahanan tidak menghadapi sebarang masalah kritikal. Hal ini sekaligus dapat memenuhi standard seperti yang telah diperuntukkan dalam undang-undang hak asasi antarabangsa.
\end{abstract}

Kata kunci: cabaran, depot tahanan, pendatang asing tanpa izin, pengurusan, tahanan, undangundang antarabangsa 


\title{
Challenges in managing illegal immigrants in Malaysian immigration detention center
}

\begin{abstract}
Most developed countries use the immigration detention center as the main instrument in controlling and expelling illegal immigrants. This instrument is also practiced in developing countries including Malaysia. There are some procedures and standards that the government should adhere to in managing detainees involving illegal immigrants as enshrined in the provisions of international law. However, the provisions of the law are sometimes difficult to fulfill due to some constraints and problems encountered. This paper is aimed at examining the challenges faced in managing illegal immigrants being detained in immigration detention centers. The study was only concentrated in the immigration detention center of Belantik, Sik, Kedah. To achieve the objective of this study, qualitative methods of in-depth interviews were used involving several officers at the Belantik detention center. In addition, researchers also used a focus group approach involving 150 detainees. The results of the interviews revealed that control over the influx of detainees, the process of identifying detainees, the difficulty of communicating with detainees, limited technology systems and the regular water supply problems was among the five challenges that had been faced by the immigration detention center. In conclusion, the government needs to monitor every immigration detention center from time to time to ensure that the detention center does not face any critical issues, whilst meeting the standards as stipulated in international human rights law.
\end{abstract}

Keywords: challenge, immigration detention center, illegal immigrants, management, detainees, international law

\section{Pengenalan}

Depot tahanan merupakan sebahagian daripada pendekatan pengusiran yang paling efektif digunakan dalam mengurus dan mengawal kemasukan pendatang asing (Caloz-Tschopp, 1997; Grant, 2011; Silverman \& Nethery, 2015; Kmak \& Seilonen, 2015). Pendekatan ini mula dipraktikan di kebanyakan negara maju seperti Amerika Syarikat, United Kingdom, Kanada, Australia dan Jepun sejak tahun 1990-an (Sampson \& Mitchell, 2013; Puthoopparambil, 2016; Arbogast, 2016). Fungsi depot tahanan ini diwujudkan sebagai tempat atau transit sementara bagi menempatkan pendatang asing yang melakukan kesalahan-kesalahan imigresen, antaranya seperti tidak mempunyai pasport atau permit yang sah, imigran yang dilarang, tinggal melebihi tempoh yang ditetapkan dan memasuki sesebuah negara secara haram (Grant, 2011). Oleh demikian, mereka dikategorikan sebagai pendatang haram atau PATI dan akan ditangkap oleh pihak berkuasa atau pihak imigresen. Mereka kemudiannya ditempatkan di depot tahanan (Peutz \& De Genova, 2010) dalam tempoh tertentu sebagai persediaan untuk dihantar semula ke negara asal (Capps et al., 2018; McGuinness \& Gower, 2018; Broeders, 2010; Paoletti, 2010).

Pendekatan pengusiran ini bukan sahaja dilaksanakan di negara-negara maju malah turut dipraktikkan di negara-negara membangun, contohnya, di Malaysia. Sejak tahun 1970-an, Malaysia sering didatangi pendatang asing termasuklah pencari suaka politik dan orang pelarian 
(Azizah, 2012). Kemasukan pendatang asing yang tidak dikawal, terutamanya melibatkan kemasukan PATI ini telah mewujudkan fenomena yang boleh mengancam keselamatan negara dan menjadi isu kritikal yang sukar untuk ditangani. Hal ini bertepatan dengan kenyataan yang dikemukakan oleh Kanapathy (2008) yang menyatakan bahawa pengurusan migrasi merupakan tanggungjawab yang kompleks dan mempunyai cabaran yang amat tinggi. Tambahan pula, faktor geopolitik dan budaya merupakan antara cabaran utama yang terpaksa dihadapi oleh pihak berkuasa dalam mengawal sempadan negara agar tidak dicerobohi PATI. Sehubungan dengan itu, kerajaan Malaysia berusaha untuk mengatasi isu ini dengan bertindak tegas dalam melaksanakan pendekatan pengusiran. Buktinya, kerajaan Malaysia telah membina sebanyak 14 buah depot tahanan di Semenanjung Malaysia dan Sarawak serta 4 buah Pusat Tahanan Sementara (Azizah, 2012).

Dalam hal ini, depot tahanan imigresen merupakan pihak yang bertanggungjawab dalam menguruskan proses penahanan dan penghantaran semula PATI ke negara asal. Mereka bertanggungjawab menguruskan tahanan agar memenuhi standard antarabangsa dan mematuhi hak asasi manusia, menguruskan perpindahan tahanan asing yang telah tamat menjalani hukuman dari penjara ke depot tahanan bertujuan untuk pengusiran, menguruskan pengusiran tahanan asing ke negara asal, bekerjasama dengan pihak agensi penguatkuasaan, pihak kedutaan asing, badan bukan kerajaan (NGO) dan agensi-agensi antarabangsa, dan menyediakan pelan kontigensi krisis bagi menangani dan mengawal sebarang ancaman dan krisis yang berlaku di depot tahanan Imigresen Malaysia. Oleh demikian, artikel ini dilakukan bertujuan bagi meneliti cabaran yang dihadapi oleh pihak depot tahanan Belantik dalam menguruskan tahanan yang terdiri daripada PATI.

\section{Kajian literatur}

\section{Kajian depot tahanan imigresen: Satu penilaian}

Pengkajian dan penulisan yang berkaitan dengan depot tahanan imigresen kebanyakannya memfokuskan kepada isu yang berlaku di negara-negara maju. Antaranya seperti di Eropah (Arbogast, 2016; Griffiths, 2015; Cornelisse, 2015; Fischer, 2015; Kmak \& Seilonen, 2015; Rifà, 2015; Mainwaring, 2015), Amerika Syarikat (Gilman \& Ramero, 2018; Haines \& Kalhan, 2015; Hamilton, 2011), Kanada (Cleveland, 2015; Chen, 2005), Korea Selatan (Lee, 2012), Jepun (Hiroshi, 2015) dan Australia (Sampson, 2015). Walaupun sudah banyak kajian dilakukan mengenai depot tahanan di negara-negara maju namun masih wujud beberapa kelompangan dalam pengkajian lepas, iaitu kurang memberi penekanan terhadap isu yang berlaku di negaranegara membangun, terutamanya di Malaysia. Oleh demikian, kajian ini dilakukan bertujuan bagi mengetahui bagaimana kerajaan Malaysia melaksanakan dasar dalam mengawal kemasukan pendatang asing dengan menggunakan kaedah pengusiran melalui depot tahanan.

Isu penahanan imigran di depot tahanan merupakan isu kontroversi yang sering dibahaskan dalam kalangan sarjana, sama ada dalam negara atau luar negara. Isu kontroversi yang menjadi perdebatan dalam kalangan pengkaji kebanyakanya memfokuskan kepada beberapa aspek, antaranya kajian yang melibatkan aspek kesihatan. Kajian yang dijalankan oleh Lorek et al. (2009), Kronick et al. (2015) dan Mares dan Jureidini (2004) mendapati bahawa penahanan yang melibatkan kanak-kanak di depot tahanan imigresen boleh mendatangkan kesan negatif terhadap fizikal dan emosi. Kanak-kanak berpotensi mengalami trauma meskipun telah dibebaskan 
(Kronick et al., 2015). Manakala, penahanan yang membabitkan golongan muda boleh menyebabkan proses perkembangan minda mereka terbantut (Dudley et al., 2012). Selain itu juga, golongan muda ini turut menghadapi kesukaran dalam menyesuaikan diri di sekolah setelah mereka dibebaskan (Fazel \& Stein, 2002).

Kajian yang merangkumi aspek undang-undang antarabangsa juga menjadi tumpuan para pengkaji, antaranya seperti yang dilakukan oleh Grant (2011), Human Rights Watch (2010), Jorgensen (2016) dan Rifà (2015). Grant (2011) berhujah bahawa penahanan yang melibatkan pelbagai warganegara, agama dan budaya boleh mencetuskan fenomena ketidaksamarataan dalam kalangan tahanan seperti diskriminasi atau layanan yang tidak adil oleh pihak pengurusan depot. Grant turut menambah bahawa penahanan seseorang imigran juga boleh menimbulkan beberapa isu yang bertentangan dengan hak asasi manusia seperti hak untuk mendapatkan khidmat guaman, doktor dan menghubungi saudara-mara atau pihak ketiga termasuk pihak konsular. Kajian yang dilakukan oleh Grant ini disokong oleh Hamilton (2011) dan Jorgensen (2016) yang mendapati bahawa wujud perlanggaran hak asasi dalam kalangan imigran yang ditahan di depot tahanan imigresen Amerika Syarikat, iaitu melibatkan perlanggaran dari segi prosedur penyiasatan, tidak berikan rawatan kesihatan, dilayan secara kasar dan tidak berperikemanusiaan serta tidak dibenarkan untuk menghubungi atau menerima lawatan dari keluarga atau saudara-mara.

Kajian yang memfokuskan kepada aspek pengurusan depot tahanan imigresen pula kurang dibahaskan dalam kalangan pengkaji. Hal ini mungkin disebabkan oleh faktor dasar penswastaan yang dilaksanakan oleh pihak kerajaan bertujuan bagi meningkatkan kecekapan dan pengasingan perusahaan awam daripada birokrasi kerajaan (Allessi, 1987). Hal ini diakui oleh Flynn dan Cannon (2009) yang menyatakan bahawa pengurusan depot tahanan imigresen telah diserahkan kepada pihak swasta untuk diuruskan. Fenomena ini berlaku di kebanyakan negara maju, antaranya seperti di negara Amerika Syarikat, Australia, Jerman dan Sweden. Oleh sebab itu, kajian mengenai pengurusan kurang dilakukan kerana dikategorikan sebagai sulit oleh sesetengah syarikat swasta. Hanya terdapat segelintir pengkaji sahaja yang memfokuskan kepada aspek pengurusan depot tahanan imigresen seperti yang dilakukan oleh Brooker et al. (2016) dan selebihnya hanya laporan yang disediakan oleh pihak kerajaan atau pihak tertentu yang mempunyai akses untuk masuk ke dalam depot tahanan sahaja seperti United Natioans Commission on Human Rights (UNCHR) dan International Organization for Migration (IOM) (Kaytazt, 2015).

Brooker et al. (2016) memfokuskan kajiannya terhadap aspek pengurusan yang melibatkan cabaran dalam menyediakan rawatan kesihatan mental di depot tahanan. Selain itu, laporan yang dikemukakan oleh pihak Homeland Security (2017), New York Lawyers for the Public Interest (2017) dan Suruhanjaya Integriti Agensi Penguatkuasa (2017) lebih menekankan kepada aspek pengurusan yang melibatkan isu kesihatan, penginapan, infrastruktur dan sistem jaringan komunikasi. Manakala, laporan yang disediakan dengan kerjasama tiga agensi, iaitu American Civil Liberties Union, Detention Watch Networt dan Heartland Alliance's National Immigrant Justice Center (2016) pula meneliti tentang punca kematian yang berlaku di depot tahanan di Amerika Syarikat dan hasil kajian mendapati bahawa punca kematian tahanan adalah disebabkan oleh faktor layanan yang buruk dan tindakan pihak pengurusan depot yang sering mengabaikan kesihatan tahanan. Oleh hal yang demikian, artikel ini dijalankan bertujuan bagi mengenal pasti cabaran yang dihadapi oleh pihak pengurusan dalam menguruskan PATI di depot tahanan Imigresen Malaysia, terutamanya di Belantik. 


\section{Metod dan kawasan kajian}

Pendekatan kualitatif berbentuk temu bual separa-struktur digunakan dalam menjalankan kajian ini. Pendekatan ini dipilih bertujuan bagi memperoleh maklumat secara mendalam (in-depth) dan menyeluruh (comprehensive) daripada informan yang ditemu bual. Selain itu, persoalan yang dikemukakan oleh penyelidik dapat diubah suai sama ada dari segi susunan dan cara menyoal agar lebih fleksibel (Sidek, 2003).

Terdapat dua kaedah pengumpulan data yang digunakan dalam kajian ini, iaitu melalui data primer dan data sekunder. Data primer diperoleh melalui kaedah temu bual bersama dengan pegawai di depot tahanan Belantik. Pada masa yang sama, penyelidik akan menggunakan kaedah kumpulan perbincangan berfokus bagi mendapatkan maklumat mengenai PATI yang ditahan di depot tahanan di Belantik, Sik. Jumlah responden bagi setiap perbincangan berfokus melibatkan seramai 150 orang tahanan yang terdiri daripada pelbagai warganegara.

Rasional pemilihan depot tahanan Belantik sebagai kawasan kajian adalah disebabkan oleh dua faktor, iaitu yang pertama ialah faktor lokasi. Kebanyakan depot tahanan yang dibina di Malaysia terletak di kawasan bandar atau pinggir bandar yang mempunyai sejumlah penduduk di kawasan sekitarnya, antaranya seperti Depot Tahanan Imigresen Bukit Jalil, Depot Tahanan Imigresen Semenyih, Depot Tahanan Imigresen Pekan Nenas dan Depot Tahanan Imigresen Tanah Merah. Namun, lokasi ini berbeza di depot tahanan Belantik kerana depot ini bukan sahaja terletak jauh di kawasan pedalaman yang kurang penduduk malah depot ini dikelilingi bukitbakau, hutan tebal dan dan terletak berhampiran dengan sempadan negara antara MalaysiaThailand.

Faktor kedua pemilihan depot tahanan Belantik sebagai kawasan kajian adalah disebabkan oleh faktor kekurangan kemudahan asas. Oleh sebab kedudukan depot tahanan Belantik yang terletak di kawasan pedalaman ini menyukarkan pihak depot untuk mendapatkan keperluan dan kemudahan asas seperti air, elektrik dan rangkaian telekomunikasi. Tambahan pula, struktur bangunan depot ini dibina berasaskan kayu dan batu sahaja. Kerja-kerja bagi menaiktarafkan bangunan dan infrastruktur baru sahaja dilakukan oleh pihak kerajaan pada akhir tahun 2015. Jika dibuat perbandingan, isu kekurangan kemudahan asas ini tidak timbul di depot tahanan imigresen yang lain. Oleh itu, faktor lokasi dan faktor kekurangan kemudahan asas ini menjadi isu yang sangat menarik untuk diteliti dan dikaji.

Manakala, data sekunder dikumpul melalui dua kaedah, iaitu secara bercetak dan tidak bercetak yang diterbitkan atau tidak diterbitkan seperti buku, dokumen sejarah, jurnal, keratan akhbar, laporan bertulis daripada pihak berkuasa, majalah dan dokumentasi perundangan. Semua maklumat yang diperoleh akan diproses dan dianalisis menggunakan analisis kandungan (content analysis), iaitu maklumat penting yang diperoleh dalam temu bual akan dikumpul dan disusun mengikut susunan tema isi (thematic sequence) dengan berpandukan kepada objektif dan persoalan kajian yang ditetapkan terdahulu. Isi-isi penting ini kemudian dipersembahkan secara kualitatif melalui penulisan yang disokong oleh fakta-fakta, kajian kes dan perbincangan secara komprehensif. Fakta-fakta yang ditemui dalam temu bual ditulis sama ada dalam bentuk kajian kes. 


\section{Hasil kajian dan perbincangan}

\section{Analisis terhadap cabaran dalam menguruskan PATI di depot tahanan imigresen}

Terdapat lima cabaran yang terpaksa dihadapi oleh pihak imigresen dalam menguruskan PATI di depot tahanan Belantik, Sik, Kedah. Antara cabaran yang pertama ialah menyediakan kemudahan penginapan kepada tahanan mengikut standard yang telah ditetapkan dalam peruntukan Pertubuhan Bangsa-Bangsa Bersatu (PBB). Menurut Peraturan 13 yang dinyatakan dalam Peraturan-peraturan Minimum Standard bagi Layanan terhadap Tahanan (Peraturan Nelson Mandela) menyebut:

“...Semua tempat tinggal yang disediakan bagi kegunaan tahanan dan terutamanya semua tempat tidur perlu memenuhi semua keperluan kesihatan, dengan memberikan perhatian sewajarnya kepada keadaan iklim dan terutamanya kepada isi padu udara, ruang lantai minimum, pencahayaan, pemanasan dan pengudaraan”.

Berdasarkan kepada kenyataan berkenaan, hal ini jelas menunjukkan bahawa tiada formula khusus atau standard yang boleh digunapakai oleh pihak pengurusan dalam menyediakan kemudahan penginapan terhadap tahanan. Malah, pihak pengurusan sukar untuk mentakrifkan ruang yang diperlukan bagi setiap tahanan memandangkan wujud perbezaan besar dalam menetapkan standard penginapan tahanan di seluruh dunia. Buktinya, wujud pelbagai variasi mengenai peraturan penginapan bagi tahanan di peringkat global, antaranya seperti, di Malta, tahanan akan ditempatkan di dua lokasi penginapan, iaitu di pusat tahanan Safi dan pusat tahanan Lyster. Kedua-dua lokasi ini dahulunya merupakan berek tentera dan kini telah dibaik pulih menjadi penempatan sementara tahanan PATI. Namun, kesesakan sering berlaku terutamanya pada musim panas. Keadaan ini menyebabkan kebanyakan tahanan terdedah kepada cuaca yang tidak menentu (Mainwaring, 2015). Manakala di Cyprus, ketiadaan kemudahan penginapan yang khusus bagi menempatkan tahanan menyebabkan mereka terpaksa ditempatkan di beberapa buah lokasi, antaranya seperti penjara, balai polis dan lapangan terbang. Namun, pada tahun 2013, pihak kerajaan Cyprus telah membina sebuah depot tahanan imigresen yang terletak di Menoyia namun hanya mampu menempatkan seramai 276 orang tahanan sahaja (Mainwaring, 2015).

Keadaan yang sama dihadapi oleh pihak pengurusan depot tahanan Belantik dalam aspek menyediakan kemudahan penginapan terhadap tahanan PATI. Depot tahanan Belantik mempunyai dua blok penginapan dengan kapasiti yang boleh memuatkan seramai 950 orang tahanan. Namun, pihak pengurusan depot tahanan kadang-kala menghadapi kesukaran dalam memastikan jumlah tahanan ini tidak melebihi dari kapasiti yang boleh menimbulkan ketidakselesaan terhadap tahanan. Ketidaktentuan dari segi jumlah tahanan dalam sesebuah depot ini dipengaruhi oleh dua faktor, iaitu lokasi dan dasar kerajaan. Depot tahanan Belantik yang terletak berhampiran dengan sempadan negara ini berpotensi menjadi lokasi utama penempatan tahanan. Kebanyakan tahanan yang ditangkap di sempadan antara MalaysiaThailand lazimnya akan ditempatkan di depot tahanan Belantik. Buktinya, hasil dari temu bual yang dijalankan terhadap 150 orang tahanan, dianggarkan seramai 62 orang tahanan ini telah ditahan di sempadan utara negara Semenanjung Malaysia. Daripada angka tersebut, seramai 45 orang ditahan di Bukit Kayu Hitam, 12 orang ditangkap di Padang Besar, 4 orang ditahan di Kuala Kedah dan seorang lagi berjaya diberkas di kawasan Changloon. Menurut Mohd Na'eim at al. (2017), sempadan antara Malaysia-Thailand menjadi destinasi dan pilihan utama bagi PATI 
yang kebanyakannya terdiri dari warganegara Bangladesh, Myanmar, Kemboja, Vietnam dan Thailand.

Faktor lokasi yang terletak berhampiran dengan sempadan utara negara ini menyebabkan depot tahanan Belantik menjadi sesak dan melebihi kapasiti yang telah ditetapkan. Fenomena ini diakui oleh wakil dari pihak depot tahanan Belantik dengan berkata:

“...Kapasiti pernah mencecah 2,000 lebih semasa kejadian bot. Langkah untuk mengatasi kepadatan tahanan ialah dengan meminta bantuan dari depot lain dan kita agihkan. Di bawah arahan daripada HQ".

Di samping itu, jumlah kapasiti sesebuah depot tahanan juga dipengaruhi oleh dasar kerajaan, contohnya, pelancaran Hari-Hari Operasi (HHO) yang mula dilaksanakan pada tahun 2014. Pendekatan yang dilaksanakan oleh pihak kerajaan bertujuan bagi menangani isu kebanjiran PATI ini telah menjadi faktor penyumbang kepada kesesakan dalam depot tahanan. Keadaan ini bukan sahaja dialami di depot Belantik malah melibatkan semua depot di seluruh Malaysia. Oleh demikian, kedua-dua faktor ini secara langsung telah mendatangkan masalah dan kesukaran terhadap pihak pengurusan depot tahanan Belantik dalam menyediakan kemudahan penginapan terhadap tahanan.

Cabaran yang kedua dihadapi oleh pihak imigresen dalam menguruskan PATI ialah mengenal pasti identiti tahanan. Berdasarkan kepada temu bual yang dijalankan, terdapat seramai 72 orang tahanan yang ditangkap dan ditahan di depot tahanan Belantik tidak mempunyai dokumen perjalanan yang sah atau memasuki Malaysia melalui pintu masuk yang tidak diwartakan. Oleh demikian, menjadi tugas pihak pengurusan depot tahanan untuk menyiasat dan mengetahui latar belakang tahanan terlebih dahulu sebelum proses penghantaran pulang dilakukan. Proses penahanan lazimnya mengambil masa yang lama seperti yang berlaku di negara Kanada, Malta dan Cyprus. Ketiga-tiga negara ini tidak menetapkan secara spesifik mengenai tempoh penahanan seseorang tahanan (Cleveland, 2015; Mainwaring, 2015). Di negara Turki pula, penahanan boleh mengambil masa selama 6 bulan atau lebih bergantung kepada kerjasama yang diberikan oleh tahanan terhadap pihak berkuasa (Kaytazt, 2015). Manakala di Finland, tempoh penahanan boleh mencecah 6 hingga 12 bulan bergantung kepada keadaan (Kmak \& Seilonen, 2015).

Terdapat empat keadaan yang menyebabkan tahanan terpaksa ditahan dalam tempoh masa yang lama, iaitu kegagalan tahanan untuk mengemukakan dokumen sama ada pasport atau visa semasa ditangkap, kegagalan tahanan untuk mendedahkan identiti negara asal, kegagalan tahanan membiayai kos pengangkutan untuk pulang ke negara asal dan penahanan seseorang tahanan yang tertakluk di bawah perintah mahkamah atau polis. Keadaan ini diakui oleh wakil informan dari pihak depot tahanan Belantik dengan berkata:

“...Kadang-kala yang menjadi masalah utama bagi pihak kami ialah tahanan tidak memberitahu kerakyatan sebenar mereka. Hal ini melambatkan proses mengenal pasti negara asal dan mengeluarkan dokumen perjalanan dari pihak kedutaan".

Malah, perkara ini pernah dijelaskan oleh Ketua Pengarah Imigresen Malaysia, Datuk Seri Mustafar Ali melalui sidang temu bualnya bersama dengan pihak Sinar Harian (Lisa Hasan \& Riduan Ashaha, 2018). Beliau mengulas mengenai isu tempoh penahanan PATI ini dengan berkata: 
“...Apabila seseorang itu ditangkap, mereka tiada dokumen, kita memerlukan dokumen mereka dari kedutaan. Kedutaan mereka akan mengeluarkan dokumen untuk membolehkan mereka dihantar pulang ke negara asal. Jika tiada dokumen langsung, mereka akan digelar sebagai warga tidak bernegara, sebagai contohnya, apabila pihak kami menghubungi kedutaan berkenaan, PATI mengatakan mereka bukan dari negara terbabit. Sama juga kedutaan yang tidak mengaku PATI tersebut warganegara mereka. Jadi, pihak kedutaan tidak akan mengeluarkan dokumen. Bila tidak dikeluarkan dokumen, berapa lama mereka terpaksa tunggu?".

Berdasarkan kepada kenyataan yang dikemukakan oleh wakil dari pihak depot tahanan Belantik dan Ketua Pengarah Imigresen ini dapat simpulkan bahawa pihak pengurusan depot tahanan bukan sahaja perlu menyiasat dan mengenal pasti identiti tahanan malah pihak pengurusan depot juga perlu menguruskan semua prosedur bermula dari awal proses penahanan sehingga proses penghantaran pulang semula tahanan ke negara asal dilakukan. Selain itu, pihak pengurusan depot perlu menyediakan senarai tahanan dan menyerahkan senarai tersebut kepada pihak kedutaan bertujuan untuk menghubungi dan mengesahkan status kewarganegaraan tahanan. Seterusnya, pihak kedutaan yang terlibat akan datang ke depot tahanan dan mengadakan sesi temu duga bersama dengan tahanan bagi urusan pengeluaran pas dan penghantaran pulang tahanan ke negara asal. Sesi pertemuan yang diadakan antara pihak kedutaan dengan tahanan merupakan pertemuan penting yang boleh menentukan tempoh penahanan seseorang tahanan sama ada mengambil masa yang panjang atau pendek. Menurut Mohamad Fauzi dan Muhd Ridhwan (2014), proses penghantaran semula PATI ke negara asal lazimnya diuruskan oleh pihak agensi yang telah mendapat kelulusan dari pihak Kementerian Dalam Negeri (KDN).

Kesukaran untuk berkomunikasi dengan tahanan merupakan cabaran ketiga yang terpaksa dihadapi oleh pihak pengurusan depot. Berdasarkan kepada temu bual yang dijalankan bersama pegawai, kebanyakan pegawai depot tahanan Belantik mengakui bahawa wujud kesukaran untuk berkomunikasi dengan tahanan. Hal ini kerana kebanyakan tahanan terdiri dari pelbagai negara, antaranya sepeti Bangladesh, Myanmar, Thailand, Indonesia, Nepal, India, Laos, Somalia dan Afrika (lihat Rajah 1). Menurut Kayzat (2015), ketiadaan jurubahasa di depot tahanan boleh menjadi faktor penghalang kepada tahanan untuk mendapatkan hak dan perkhidmatan. Malah, keadaan ini turut diakui oleh Mohd Na'eim et al. (2017) yang berhujah bahawa kebanyakan PATI tidak tahu membaca melainkan bahasa ibunda. 


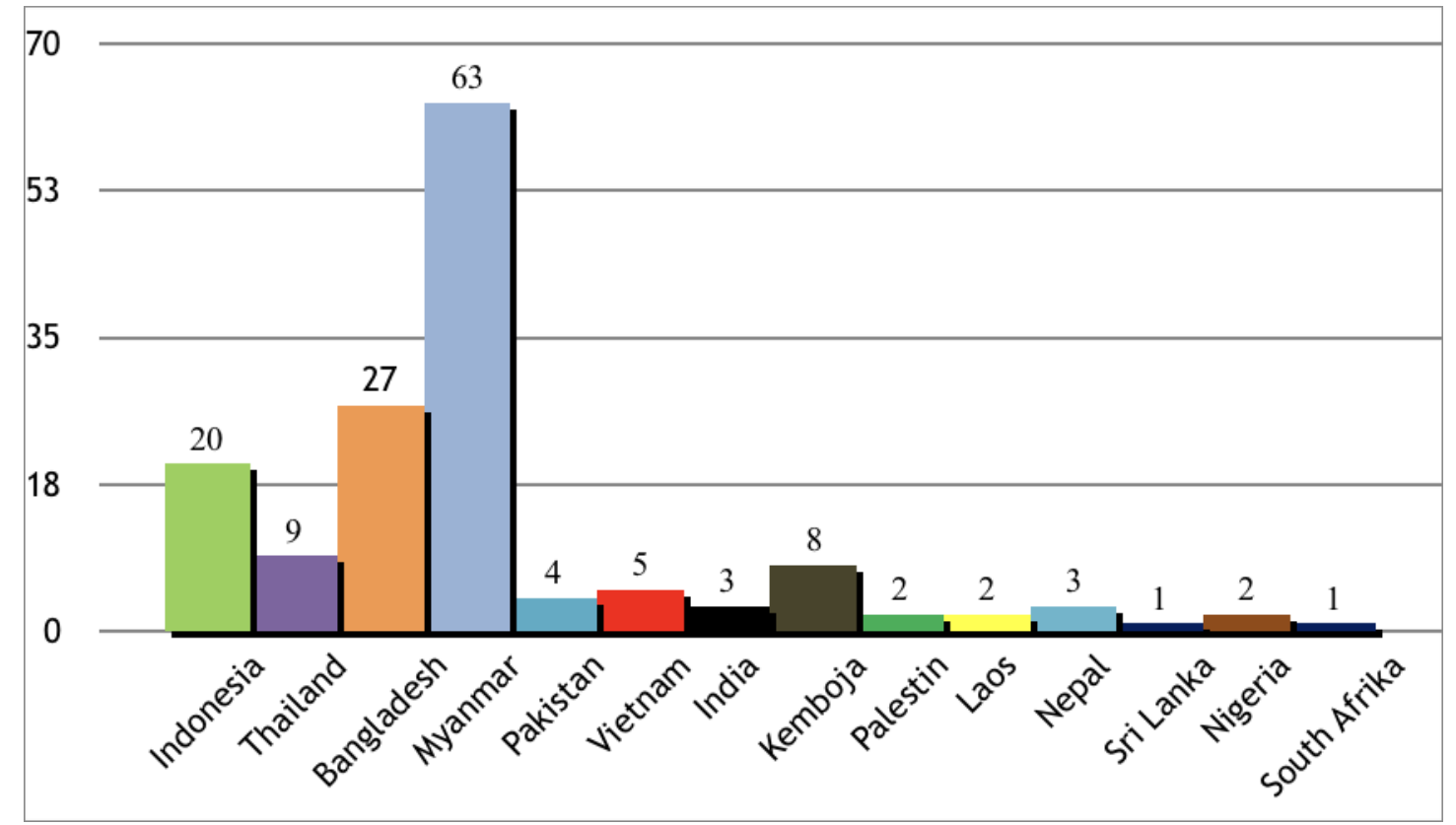

Rajah 1. Statistik tahanan yang ditahan di depot tahanan Imigresen Belantik mengikut negara asal sepanjang bulan Mac 2017

Di samping itu, kebanyakan tahanan PATI yang ditahan di depot tahanan Belantik berasal dari negara dunia ketiga yang tidak mempunyai taraf berpendidikan yang baik. Buktinya, hasil daripada temu bual yang dijalankan terhadap 150 orang tahanan, didapati bahawa seramai 63 orang tahanan berasal dari negara Myanmar, 27 orang tahanan dari negara Bangladesh dan 20 orang dari negara Indonesia (lihat Rajah 2). Sebahagian besar daripada jumlah tersebut, sebanyak 44 orang tahanan ini mengakui bahawa mereka tidak pernah bersekolah. Manakala sebahagiannya lagi hanya bersekolah sehingga usia 10 tahun sahaja. Oleh hal yang demikian, kebanyakan tahanan bukan sahaja tidak pandai berbahasa Melayu malah tidak berbahasa Inggeris. Namun tidak dapat dinafikan bahawa terdapat segelintir daripada mereka boleh berbahasa Melayu namun tidak begitu fasih untuk bertutur. Keadaan ini boleh mewujudkan salah faham dan menimbulkan kerumitan, terutamanya urusan melibatkan penghantaran semula pulang tahanan ke negara asal.

11 tahun \& ke atas

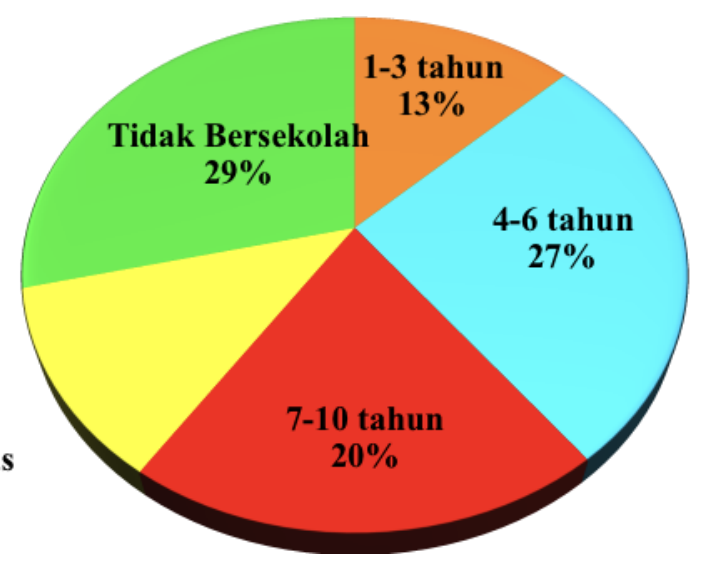

Rajah 2. Taraf pendidikan tahanan yang ditahan di depot tahanan Belantik sepanjang bulan Mac 2017 
Selain dari cabaran dalam mengenal pasti identiti tahanan, pihak pengurusan depot juga terpaksa berdepan dengan masalah rangkaian teknologi yang terhad. Faktor geografi dan bentuk muka bumi seperti bukit-bakau dan hutan belantara yang wujud di sekeliling depot tahanan Belantik menyebabkan jaringan telekomunikasi tidak dapat berfungsi dengan baik. Buktinya, pihak pengurusan depot menghadapi kesukaran dalam menguruskan pendaftaran kemasukan tahanan. Hal ini kerana proses pendaftaran kemasukan tahanan perlu dilakukan melalui kaedah sistem biometrik secara atas talian. Namun, jaringan internet yang terhad menyebabkan sistem pendaftaran tergendala dan melambatkan urusan-urusan lain. Selain itu juga, pihak pengurusan depot turut menghadapi masalah berkaitan dengan liputan telekomunikasi yang sedia ada sama ada melibatkan talian tetap atau talian mudah alih. Keadaan ini sudah tentu akan menimbulkan kesukaran kepada pihak pihak pengurusan depot untuk menghubungi pihak luar seperti ada pihak kedutaan, pihak kesihatan, pihak pendakwa raya dan pihak-pihak lain yang terlibat dalam menguruskan tahanan.

Di samping itu, ketiadaan bekalan air juga turut membebankan pihak pengurusan depot Belantik dalam menguruskan tahanan. Menurut pihak pengurusan depot tahanan, keadaan ini berlaku disebabkan oleh beberapa faktor, antaranya seperti perancangan dan reka bentuk yang tidak sesuai; infrastruktur tidak mencukupi atau tidak diselenggara dengan baik; bilangan tahanan yang ramai dan peningkatan bilangan tahanan; kos yang tinggi untuk menghantar bekalan mencukupi, terutamanya ketika musim kering dan panas; gangguan dalam bekalan air; kekurangan belanjawan penyelenggaraan; atau masalah pembayaran yuran kepada pihak berkuasa tempatan. Ketiadaan bekalan air ini turut diakui oleh kebanyakan tahanan dan kakitangan pihak pengurusan depot dengan menyatakan bahawa depot tahanan Belantik sering menghadapi masalah ketiadaan bekalan air, terutamanya ketika musim kemarau. Keadaan ini bukan sahaja menimbulkan keresahan dalam kalangan kakitangan pihak pengurusan depot tahanan malah merumitkan aktiviti harian tahanan, contohnya, keperluan air digunakan bertujuan untuk diminum, untuk memasak, membasuh perkakas, kebersihan diri, pembuangan kumbahan dan pembersihan.

\section{Kesimpulan}

Hasil daripada perbincangan yang telah dijalankan bersama dengan pihak-pihak yang terlibat dalam menguruskan tahanan PATI di depot tahanan, penyelidik mendapati bahawa terdapat lima cabaran iaitu kesukaran dalam menyediakan penginapan kepada tahanan, kesukaran mendapatkan maklumat peribadi tahanan, isu bahasa, rangkaian teknologi yang terhad dan ketiadaan bekalan air merupakan antara cabaran utama dalam menguruskan tahanan di depot tahanan Belantik. Menurut pihak imigresen depot tahanan, cabaran dari segi keselamatan yang melibatkan rusuhan dan pergaduhan besar dalam kalangan tahanan tidak pernah berlaku di depot tahanan Belantik. Kadang-kala wujud pergaduhan kecil antara tahanan akibat daripada salah faham dan rasa tidak puas hati dalam kalangan tahanan. Namun, isu tersebut masih lagi dapat dikawal oleh pihak pengurusan depot tahanan.

Manakala, isu yang berkaitan dengan penambahbaikan dari segi kelengkapan teknologi dan sistem bekalan air yang sering terjejas perlu ditangani segera oleh pihak depot tahanan. Kajian ini mengesyorkan kepada pihak imigresen depot supaya mengadakan perbincangan dengan pihak Syarikat Air Darul Aman Sdn. Bhd. (SADA) untuk menyelesaikan masalah gangguan bekalan air. Selain itu, pihak imigresen depot perlu mengadakan perbincangan dengan pihak National 
Blue Ocean (NBOS) dengan agensi lain bagi membantu dalam memudahkan urusan pengusiran tahanan ke negara asal. Di samping itu, pihak imigresen depot perlu mengadakan perbincangan dengan pihak Telekom Malaysia (TM) bagi menyelesaikan masalah berkaitan dengan rangkaian telekomunikasi sama ada untuk talian tetap, mudah alih atau internet.

Walaupun terdapat pelbagai isu dan masalah yang wujud di depot tahanan namun, pihak imigresen perlu memastikan tahap keperluan, kebersihan, kesihatan dan keselamatan tahanan terjamin selaras dengan standard dan prosedur yang telah ditetapkan oleh Pertubuhan BangsaBangsa Bersatu (PBB). Hasil daripada temu bual yang dilakukan, pihak depot menegaskan bahawa pihaknya akan memastikan semua tahanan berada dalam keadaan sihat sama ada sebelum dan selepas dibenarkan pulang ke negara asal. Mereka tidak membenarkan mana-mana tahanan yang sakit dihantar pulang begitu sahaja. Jika tahanan mengalami kecederaan, kecelakaan atau kematian dalam tahanan, pihak imigresen depot perlu bertanggungjawab dalam kes sedemikian. Keadaan ini bukan sahaja menjejaskan proses pengusiran seseorang tahanan dan menjejaskan kredibiliti pihak imigresen depot malah membawa kerugian kepada negara kerana terpaksa menanggung kos terutamanya dari segi kos perubatan dan kos pengebumian. Oleh sebab itu, isu dalam menguruskan tahanan asing tidak boleh dianggap sebagai remeh dan dilakukan secara lewa kerana isu ini boleh menjejaskan hubungan diplomatik antara kedua-dua negara yang terlibat.

\section{Rujukan}

Allessi, De Louise. (1987). Property rights and privatisation. New York, The America Academy of Political and Social Science.

American Civil Liberties Union, Detention Watch Network, \& Heartland Alliance's National Immigrant Justice Center (2016). Fatal neglect: How ICE ignore deaths in detention. Retrived from https://www.detentionwatchnetwork.org

Arbogast, L. (2016). Migrant detention in the European Union: A thriving business: Outsourcing and privatisation of migrant detention. Migreurop. Rosa-Luxemburg-Stiftung, Brussels Office.

Azizah Kassim. (2012). Dasar pekerja asing di Malaysia: Perlunya anjakan paradigm. Bangi, Universiti Kebangsaan Malaysia.

Broeders, D. (2010). Return to sender? Administrative detention of irregular migrants in Germany and the Netherlands. SAGE Journals, 12(2), 169-186.

Brooker, S., Albert, S., Young, P., \& Steel, Z. (2016). Challenges to providing mental health care in immigration detention (Global Detention Project Working Paper 19).

Caloz-Tschopp, MC. (1997). On the detention of aliens: the impact on democratic rights. Journal of Refugee Studies, 10(2), 165-180.

Capps, R., Chishti, M., Gelatt, J., Bolter, J., \& Soto, A.G.R. (2018). Revving up the deportation machinery: Enforcement and push back under Trump. Migration Policy Institute (MPI).

Chen Wendy. (2005). Crime, deportation and the regulation of immigrants in Canada. Crime, Law and Social Change, 44(2), 153-180.

Cleveland, J. (2015). Not so short and sweet: immigration detention in Canada. In Nethery, A \& Silverman, S.J. (Eds.), Immigration detention: The immigration of a policy and its human impact. New York, Routledge. 
Cornelisse, G. (2015). Guarding the external border: immigration detention in the Netherlands. In Nethery, A., \& Silverman, S.J. (Eds.), Immigration detention: The immigration of a policy and its human impact. New York, Routledge.

Depot Tahanan Belantik, Sik, Kedah. (2017, Ogos 2). Personal Interview.

Dudley, M., Steel, Z., Mares, S., \& Newman, L. (2012). Children and young people in immigration detention. Curr Opin Psychiatry, 25(4), 285-292.

Fazel, M., \& Stein, A. (2002). The mental health of refugee children. Arch Dis Child, 87(5), 36670.

Fischer, N. (2015). Games of law and repression: immigration detention in France. In Nethery, A., \& Silverman, S.J. (Eds.), Immigration detention: The immigration of a policy and its human impact. New York, Routledge.

Flynn, M., \& Cannon, C. (2009). The privatisation of immigration detention: Towards a global view. Global detention on health of children and families in the UK. Adoption \& Fostering Journal, 34(1), 88-91.

Gilman, D., \& Ramero, L.A. (2018). Immigration detention, Inc. Journal on Migration and Human Security, $X X(\mathrm{X}), 1-16$.

Grant, S. (2011). Immigration detention: Some issues of inequality. The Equal Rights Review, 7.

Griffiths, M. (2015). 'A proud tradition'? Immigration detention in the United Kingdom. In Nethery, A., \& Silverman, S.J. (Eds.), Immigration detention: The immigration of a policy and its human impact. New York, Routledge.

Haines, C.E., \& Kalhan, A. (2015). Detention of asylum seekers en masse: immigration detention in the United States. In Nethery, A., \& Silverman, S.J. (Eds.), Immigration detention: The immigration of a policy and its human impact. New York, Routledge.

Hamilton, K.R. (2011). Immigrant detention centers in the United States and international human rights. Berkeley La Raza Law School, 21(4), 93-132.

Hiroshi, Miyauchi. (2015). Immigration detention in Japan: Standing on a crossroad. Migration Policy Review, 7. 212-225.

Homeland Security. (2017). Concerns about ICE detainee treatment and care at detention facilities. Office of inspector general.

Human Rights Watch. (2010). Detained and at risk sexual abuse and harassment in United States immigration detention.

Jorgensen, C. (2016). Immigrant detention in the United States violations of International and human rights law. Retrieved from http://hrbrief.org

Kanapathy, V. (2008). Controlling irregular migration: The Malaysian experience International Labour Organization (Working Paper Series No. 14). Bangkok, ILO Asian Regional programme on governance of labour migration.

Kaytazt, E.S. (2015). At the border of 'Fortress Europe': Immigration detention in Turkey. In Nethery, A., \& Silverman, S.J. (Eds.), Immigration detention: The immigration of a policy and its human impact. New York, Routledge.

Kmak, M., \& Seilonen, A. (2015). Balancing control with rights: Immigration detention in Finland. In Nethery, A., \& Silverman, S.J. (Eds.), Immigration detention: The immigration of a policy and its human impact. New York, Routledge.

Kronick, R., Rousseau, C., \& Cleveland, J. (2015). Asylum-seeking children's experiences of detention in Canada: A qualitative study. Am J Orthopsychiatry, 85(3), 287-294. 
Lee, Woosung. (2012). The Koreans' migration to the Russian far-east and their deportation to central Asia: From the 1860s to 1937. (Master dissertation). Retrieved from University of Oregon, United States.

Lisa Hasan \& Riduan Ashaha. (2018). Sampai bila mahu tanggung PATI? Sinar Harian (pp. 45).

Lorek, A., Ehntholt, K., Nesbitt, A., Wey, E., Githinji, C., Rossor, E., \& Wickramasinghe, R. (2009). The mental and physical health difficulties of children held within a British immigration detention center: a pilot study. Child Abuse \& Neglect, 33(9), 573-585.

Mainwaring, C. (2015). Fortfying the European Union? Immigration detention in Malta and Cyprus. In Nethery, A., \& Silverman, S.J. (Eds.), Immigration detention: The immigration of a policy and its human impact. New York, Routledge.

Mares, S., \& Jureidini, J. (2004). Psychiatric assessment of children and families in immigration detention-clinical, administrative and ethical issues. Aust N Z J Public Health, 28(6), 520526.

McGuinness, T., \& Gower, M. (2018). Immigration detention in UK: An overview. House of commans library. 7294.

Mohamad Fauzi Sukimi \& Muhd Ridhwan Sarifin. (2014). Negara, undang-undang dan tenaga kerja asing: Antara ideal dan realiti di Malaysia. Geografia - Malaysian Journal of Society and Space, 10(1), 101-109.

Mohd Na'eim Ajis, Zawiyah Md. Zain, Mohamad Faisol \& Ummu Atiyah Ahmad Zakuan. (2017). Aktiviti penyeludupan migran dalam kalangan pendatang asing tanpa izin (PATI) di Malaysia. Geografia - Malaysian Journal of Society and Space,13(2), 13-25.

New York Lawyers for the Public Interest. (2017). Detained and denied: NYLPI releases report spotlighting access to healthcare in immigration detention. Retrieved from https://www.nylpi.org

Paoletti, E. (2010). Deportation, non-deportability and ideas of membership (Refugee Studies Centre Working Paper Series 65). Oxford, Refugee Studies Centre.

Peutz, N.M., \& De Genova, N. (2010). Introduction. In De Genova, N. dan Peutz, N. (Eds.), The deportation regime: Sovereignty, space and the freedom of movement. Durham, Duke University Press.

Puthoopparambil, S.J. (2016). Life in immigration detention centers: An exploration of health of immigrant detainees in Sweden and three other EU member states (PhD dissertation). Uppsala Universitet, Sweden.

Rifà, N.T. (2015). Human rights within immigration detention centers in Europe: Comparative case study of Spain, Italy and Sweden. Barcelona, Universitat Pompeu Fabra.

Rusniah Ahmad, Mohd Na'eim Ajis \& Saadon Awang. (2014). Permasalahan pendatang asing tanpa izin di Malaysia dari aspek sosial dan perundangan. Kanun: Jurnal Undang-Undang Malaysia, 26(2), 173-191.

Sampson, R. (2015). Mandatory, non-reviewable, indefinite: Immigration detention in Australia. In Nethery, A., \& Silverman, S.J. (Eds), Immigration detention: The immigration of a policy and its human impact. New York, Routledge.

Sampson, R.C., \& Mitchell, G. (2013). Global trends in immigration detention and alternatives to detention: Practical, political and symbolic rationales. Journal on Migration and Human Security, 1(3), 97-121.

Sidek Mohd Noah. (2003). Reka bentuk penyelidikan: Falsafah, teori dan praktis. Serdang, Universiti Putra Malaysia. 
Silverman, S.J. \& Nethery, A. (2015). Immigration detention: The immigration of a policy and its human impact. New York, Routledge.

Suruhanjaya Integriti Agensi Penguatkuasaan. (2017). Laporan Tahunan 2017 Annual Report. Suruhanjaya Integriti Agensi Penguatkuasaan. 